\title{
A Diverse Assemblage of Late Cretaceous Dinosaur and Bird Feathers from Canadian Amber
}

Ryan C. McKellar, ${ }^{1 *}$ Brian D. E. Chatterton, ${ }^{1}$ Alexander P. Wolfe, ${ }^{1}$ Philip ]. Currie ${ }^{2}$

The fossil record of early feathers has relied on carbonized compressions that lack fine structural detail. Specimens in amber are preserved in greater detail, but they are rare. Late Cretaceous coal-rich strata from western Canada provide the richest and most diverse Mesozoic feather assemblage yet reported from amber. The fossils include primitive structures closely matching the protofeathers of nonavian dinosaurs, offering new insights into their structure and function. Additional derived morphologies confirm that plumage specialized for flight and underwater diving had evolved in Late Cretaceous birds. Because amber preserves feather structure and pigmentation in unmatched detail, these fossils provide novel insights regarding feather evolution.

A lthough amber offers unparalleled preservation of feathers (1-4), only isolated specimens of uncertain affinity have been reported from the Late Cretaceous (5). This contrasts with the rich Early Cretaceous compression assemblage from northeastern China (6-8), leav- ing a substantial temporal gap in our understanding of feather evolution. Late Cretaceous amber from Grassy Lake, Alberta (late Campanian), is derived from lowland cupressaceous conifer forests that occupied the margin of the Western Interior Seaway and is best known for its diverse insect inclusions (9). Eleven feather or protofeather specimens (10) were recovered by screening over 4000 Grassy Lake amber inclusions predominantly within the Royal Tyrrell Museum of Palaeontology (TMP) and University of Alberta (UALVP) collections. These fossils have disparate morphologies that span four evolutionary stages for feathers $(11,12)$. Specimens include filamentous structures similar to the protofeathers of nonavian dinosaurs that are unknown in modern birds (13-15), as well as derived bird feathers displaying pigmentation and adaptations for flight and diving.

The currently accepted $(11,12)$ evolutionarydevelopmental model for feathers (Fig. 1A) consists of a stage I morphology characterized by a single filament: This unfurls into a tuft of filaments (barbs) in stage II. In stage III, either some tufted barbs coalesce to form a rachis (central shaft) (IIIa), or barbules (segmented secondary

${ }^{1}$ Department of Earth and Atmospheric Sciences, University of Alberta, Edmonton, Alberta T6G 2E3, Canada. ²Department of Biological Sciences, University of Alberta, Edmonton, Alberta T6G 2E9, Canada.

*To whom correspondence should be addressed. E-mail: rcm1@ualberta.ca

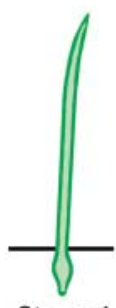

Stage I
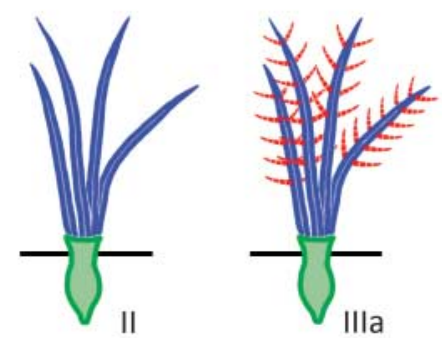

IIIa

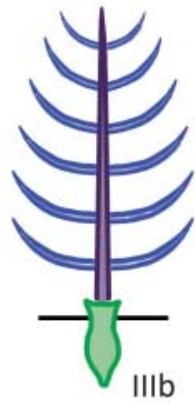

IIIb

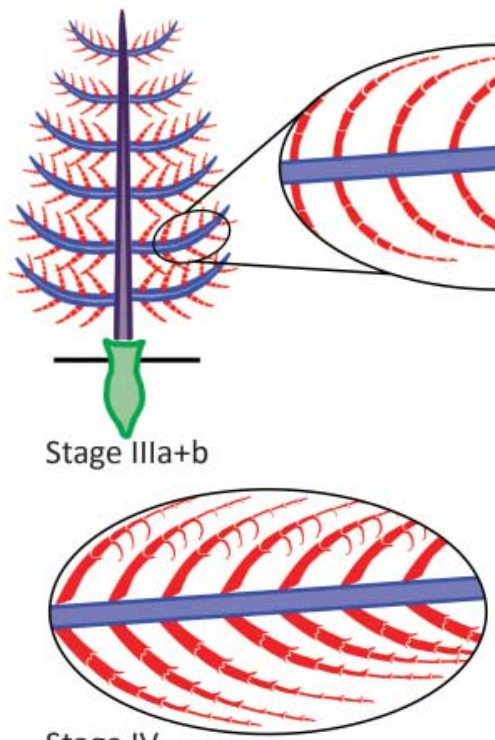

A Stage IV

Fig. 1. Feather evolutionary-developmental model (11), terminology (17), and stage I and II specimens from Canadian amber. (A) Feather stages outlined within text. Green, calamus or equivalent; blue, barbs; purple, rachis; red, barbule internodes; d.b., distal barbules; r., ramus; p.b., proximal barbules. (B) Field of fila-

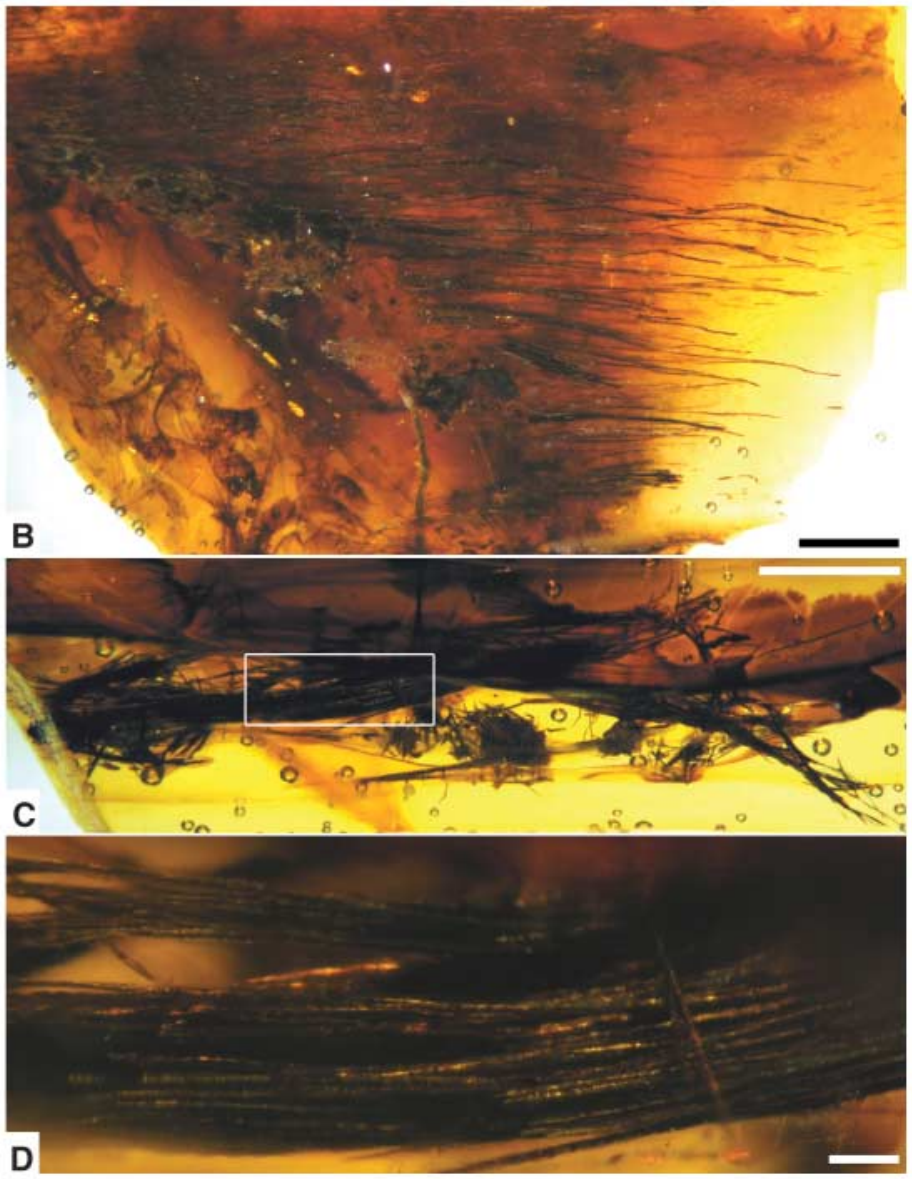

ments cut obliquely (stage I), UALVP 52821. (C) Filament clusters variably oriented (stage II), UALVP 52822. (D) Close-up of (C), showing filaments that comprise clusters. Pigmentation coupled with comparatively thick outer walls produces darker color than in isolated filaments. Scale bars, (B) and (C) $1 \mathrm{~mm}$, (D) $0.1 \mathrm{~mm} \mathrm{(10).}$ 
branches) stem from the barbs (IIIb); then, these features combine to produce tertiary branching $(\mathrm{III}+\mathrm{b})$. Barbules later differentiate along the length of each barb, producing distal barbules with hooklets at each node to interlock adjacent barbs and form a closed pennaceous (vaned) feather (stage IV). Stage V encompasses a wide range of additional vane and subcomponent specializations. Most modern birds possess stage IV or $\mathrm{V}$ feathers or secondary reductions from these stages $(11,16)$. Modern feathers exhibit a range of morphologies that are associated with their various functions and remain discernible in some of their finest subunits, the barbules (17). This is particularly important in the study of amber-entombed feathers because preservation is biased toward feather subcomponents, which provide the basis for our morphological comparisons.

Stage I is represented by UALVP 52821, which contains a dense forest of regularly spaced, flexible filaments with a mean diameter of $16.4 \pm$ $4.2 \mu \mathrm{m}$ (Fig. 1B and figs. S1 to S4). Filaments are hollow with the internal cavity comprising $\sim 60 \%$ of total diameter, have no obvious internal pith, and taper apically. Where surface texture is observable, filaments bear a faint crosshatching pattern but lack surface topography. The filaments are not plant or fungal remains because they lack cell walls and are relatively large. Comparatively small diameters and a lack of cuticular scales imply that they are not mammalian hairs, as does direct comparison to a hair from this amber deposit. Their closest morphological match is the filamentous covering found of nonavian dinosaurs such as the compsognathid Sinosauropteryx prima (18). The amber-entombed specimens are slightly finer than those of Sinosauropteryx, which may have been distorted by compression and permineralization. The amber filaments display a wide range of pigmentation, ranging from nearly transparent to dark (fig. S2). No larger-scale color patterns are apparent. [Additional specimen details are provided in supporting online material (SOM) text.]

The stage II morphotype (Figs. 1, C and D, and fig. S5) consists of tightly adpressed clusters approximately $0.2 \mathrm{~mm}$ in width and composed of filaments that are otherwise similar to those already discussed (10). Five clusters are preserved together in UALVP 52822. As in stage II primitive feathers (11), filaments in each cluster appear to diverge from a common basal region without branching, but no rachis is visible where the clusters exit the amber. These filaments bear some resemblance to fibrils that compose pycnofibers (tufted filaments) in pterosaur compression fossils (19), except the amber specimens lack the secondary organization observed in pycnofiber bundles. The most morphologically comparable compression fossils are protofeathers associated with the dromaeosaurid Sinornithosaurus millenii $(10,20)$. These clusters exhibit generally comparable sizes and shapes to the amber specimens and even have the more loosely bundled appearance distally where individual filaments have more variable lengths.

In contrast to stages I and II, additional specimens from Canadian amber have barbules specialized for discrete functions. In TMP 96.9.334 (Figs 2, A to C, and figs. S6 and S7) (10), a thick-
Fig. 2. Specialized barbules in Canadian amber. (A) Coiled barbules surrounding thickened rachis (arrow), cut obliquely, TMP 96.9.334. (B) Closeup of coils in isolated barbule. (C) Semi-flattened internodes and weakly expanded node of (A). Diffuse, variable barbule pigmentation produces pale overall color. (D) Isolated barb with differentiated barbules and thickened ramus, in spider's web, UALVP 52820. (E) Barbules near distal tip of (D), with clearly defined distal and proximal barbule series (left and right sides of ramus, respectively). (F) Closeup of distal barbule in (E), showing nodal prongs and ventral tooth on basal plate (arrow) adjacent to abrupt transition into pennulum. Banded pattern of dark pigmentation within basal plate, and diffuse dark pigmentation within pennulum, suggest a gray or black feather (24). Scale bars, (A) $0.4 \mathrm{~mm}$; (B), (D), and (E) $0.2 \mathrm{~mm}$; (C) and (F) $0.05 \mathrm{~mm}$ (10).
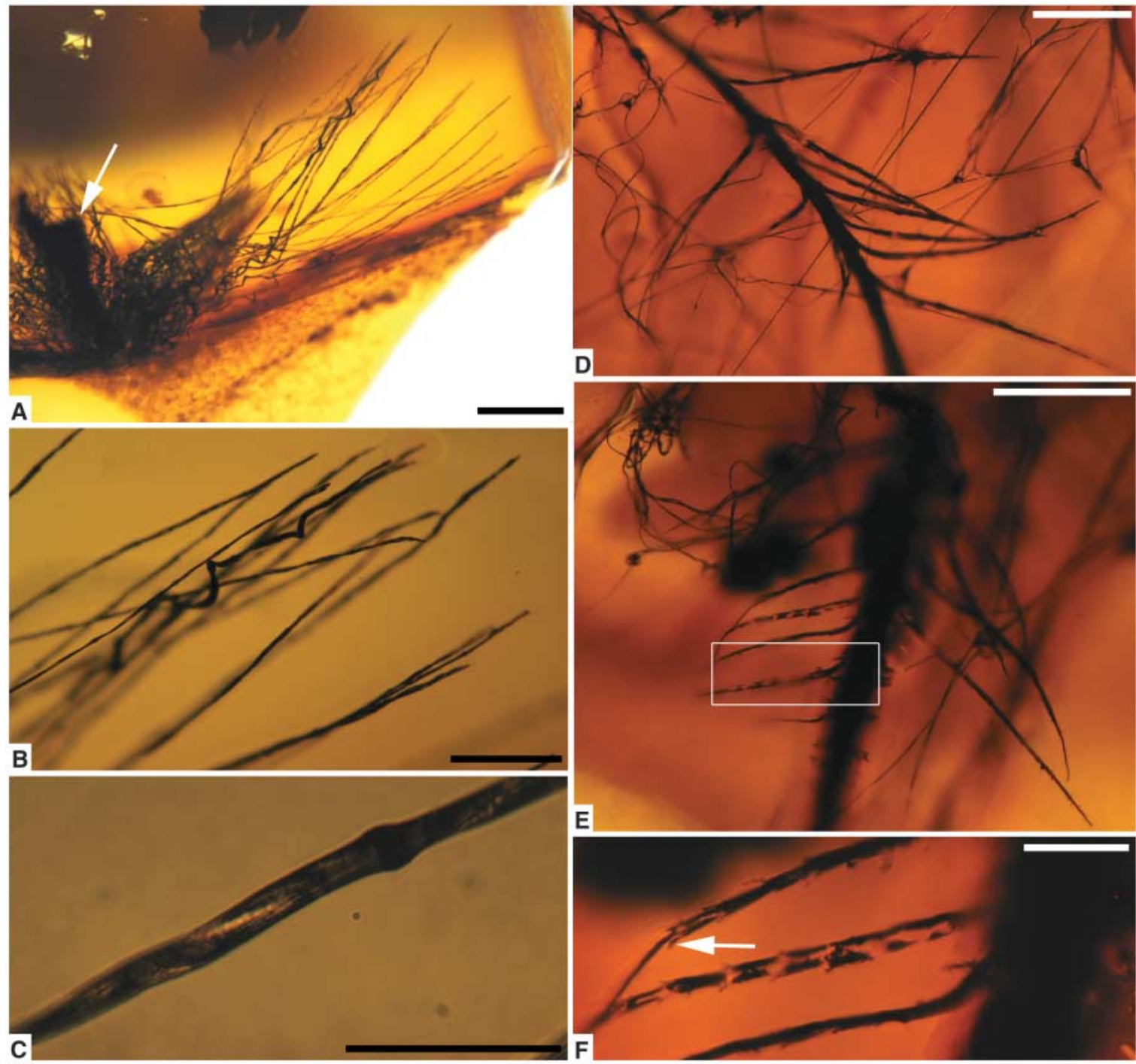
ened rachis is surrounded by numerous barbules with tightly coiled bases. The barbules undergo three or more complete whorls and are composed of semi-flattened internodes $(\sim 120 \mu \mathrm{m}$ long, $9 \mu \mathrm{m}$ wide) separated by weakly expanded nodes $(\sim 12 \mu \mathrm{m}$ wide). This coiling cannot be attributed to interaction between barbules and resin during amber polymerization because it only occurs at the base of each barbule. Mod- ern seedsnipes and sandgrouse $(21,22)$ possess belly feathers with similar basal barbule coiling, which allows water to be retained for transport to the nest for distribution to nestlings or for cooling incubating eggs. Grebes also have coiled barbules that absorb water into plumage, facilitating diving by modifying buoyancy, reducing hydrodynamic turbulence, and improving insulation (23). In all of these instances, the keratin of coiled barbules interacts with water to uncoil and absorb water through capillary action (22). The high number of coils in TMP 96.9.334 is most similar to that reported from grebes $(23,24)$, implying that the Cretaceous barbules are related to diving behavior.

Barbules displaying all characteristics necessary for forming vaned feathers are also present in Canadian amber (Fig. 2, D to F, and fig. S8)
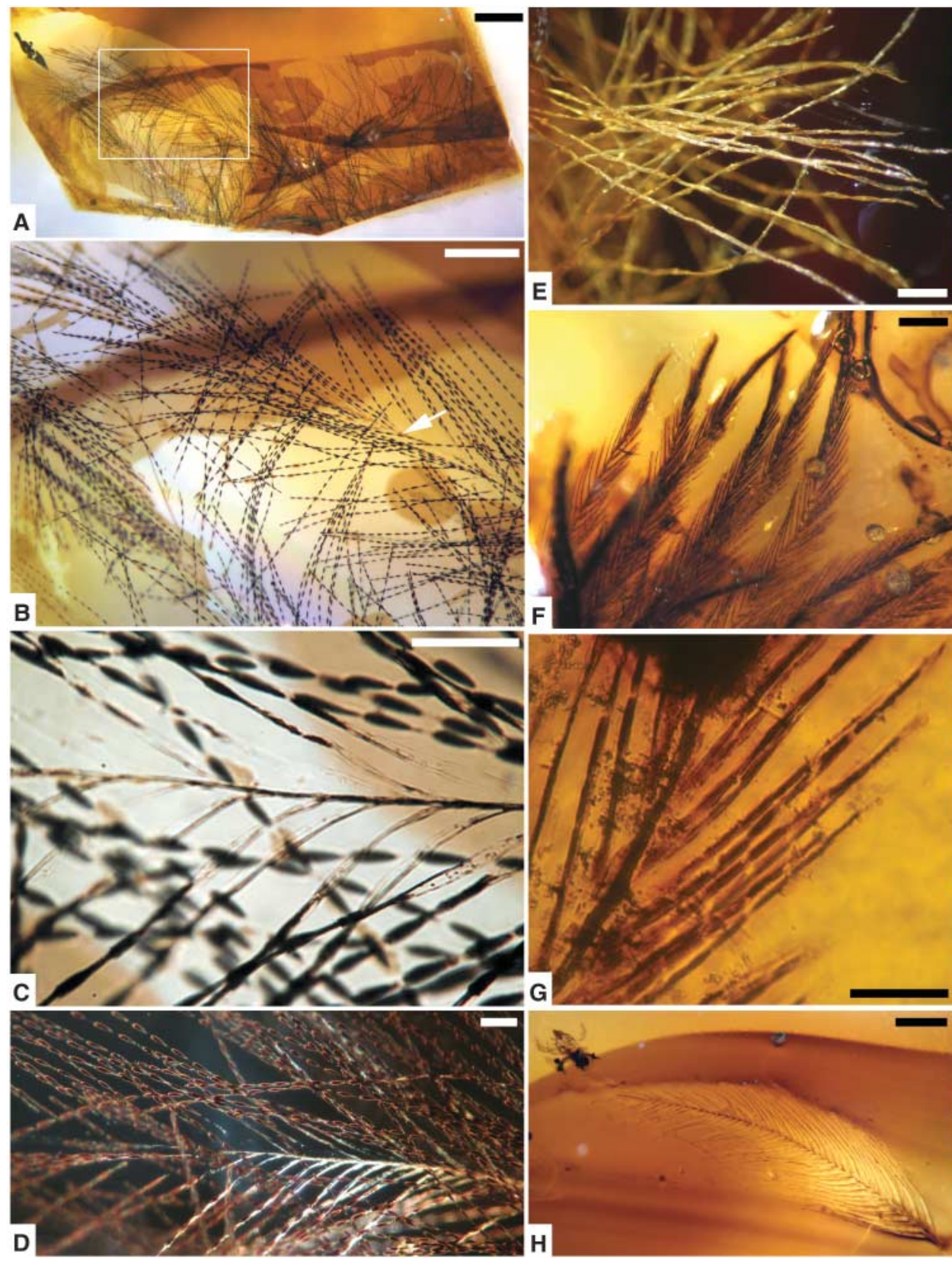

Fig. 3. Pigmentation in Canadian amber feathers. (A to $\mathbf{D})$ Semi-pennaceous feathers, TMP 96.9.997: (A) six barbs; (B) close-up of box in (A), arrow indicates unpigmented ramus; (C) detail of ramus and barbule bases; (D) dark-field microphotograph of $(C)$, showing brown coloration with ramus and basal internodes minimally pigmented. Density and distribution of pigments $(24,25)$ are consistent with medium- to dark-brown modern feathers. (E) Unpigmented downy barbules, TMP 79.16.12. (F to K) Poorly differentiated, flattened barbules: (F) partial overview of 16 pennaceous barbs, TMP 96.9.553; (G) close-up of (F), showing variable, diffuse pigmentation within barbule bases (ventral plates translucent, dorsal flanges pigmented); $(\mathrm{H})$ unpigmented, isolated barb with juvenile mite, TMP 96.9.546; (I) central portion of isolated barb, TMP 94.666.15; (]) dark-field microphotograph of (I), showing overall color; (K) banded pigmentation within basal plate of proximal barbule in (I), indicating 5 to 6 component internodes. (L) Reduced pennaceous barbs from non-interlocking region of dark brown and white mottled chicken contour feather for comparison. Scale bars, (A) $0.5 \mathrm{~mm}$; (B), (E), (F), (H) to (J), and (L) $0.2 \mathrm{~mm}$; (C), (D), (G), and (K) $0.04 \mathrm{~mm}$. 
(10). These were probably borne by an animal capable of flight. Within UALVP 52820, barbules of unequal lengths arise from either side of the barb, producing a differentiated series of longer proximal $(\sim 0.42 \mathrm{~mm})$ and shorter distal $(\sim 0.24 \mathrm{~mm})$ elements, all having spinose nodal projections. Barbules are widely spaced along a thick ramus (barb shaft) adapted for rigidity and are strongly differentiated to interlock with adjacent barbs to form a vane (10).

On the basis of the presence of a rachis in TMP 96.9.334 and differentiated barbules in UALVP 52820, these specimens can be assigned conservatively to stages IV and V and are attributed to Late Cretaceous birds. The remaining six feathers are fragmentary downy and contour feathers (Fig. 3). Although they offer limited insight concerning the identity or behavior of their bearer, their structure and pigmentation bear directly on feather evolutionary stages. Four of the six feather fragments in TMP 96.9.997 (Fig. 3, A to D, and fig. S9) are aligned. Superficially, these exhibit an intermediate morphology (stage $\mathrm{IIb}$ ) proposed for an Early Cretaceous (late Albian) French amber specimen (4). In the Canadian specimens, as in the French material, the main axis preserved is short $(3.7 \mathrm{~mm})$ and weakly defined, dorsoventrally flattened, and composed of fused secondary branches in an opposite arrangement. However, in the Canadian specimens intense pigmentation in each internode produces a beaded appearance, highlighting segmentation that is otherwise difficult to discern based on barbule diameter variation (Fig. 3C). Segmentation identifies the finest branches as barbules attached to narrow rami, and not barb equivalents attached to a rachis. This interpretation identifies these small specimens as subcomponents of a larger feather, such as basal barbs on a contour feather (17), and not a distinct stage in feather evolution lacking barbules (4). This interpretation probably extends to the French material as well. Pigmentation is preserved with fidelity in all additional specimens. Although downy feathers are consistently transparent, and would have been white in life, pennaceous feathers are more variable, with diffuse, transparent, and mottled patterns of pigmentation (Fig. 3, E to L) that match those observed in modern birds $(10,24,25)$.

Although neither avian nor dinosaurian skeletal material has been found in direct association with amber at the Grassy Lake locality, fossils of both groups are present in adjacent stratigraphic units. Hadrosaur footprints are found in close association with the amber, and younger (late Campanian and Maastrichtian) strata of western Canada contain diverse nonavian dinosaur (26) and avian $(27,28)$ remains. There is currently no way to refer the feathers in amber with certainty to either birds or the rare small theropods from the area (26). However, the discovery of endmembers of the evolutionary-developmental spectrum in this time interval, and the overlap with structures found only in nonavian dinosaur compression fossils, strongly suggests that the proto- feathers described here are from dinosaurs and not birds. Given that stage I filaments were present in densities relevant for thermoregulation and protection, and that comparable structures are preserved as coronae surrounding compression fossils, it becomes apparent that protofeathers had important nonornamental functions. Specialized barbule morphologies, including basal coiling, suggest that Campanian feather-bearers had already evolved highly specialized structures similar to those of modern grebes to enhance diving efficiency.

Canadian amber provides examples of stages I through Vof Prum's (11) evolutionary-developmental model for feathers. None of the additional morphotypes observed in compression fossils of nonavian dinosaurs $(8,15)$ or amber $(4)$ were found here, suggesting that some morphotypes may not represent distinct evolutionary stages, or may not have persisted into the Late Cretaceous. The snapshot of Campanian feather diversity from Canadian amber is biased toward smaller feathers, subcomponents of feathers, feathers that are molted frequently, and feathers in body positions that increase their likelihood of contacting resin on tree trunks. Despite these limitations, the assemblage demonstrates that numerous evolutionary stages were present in the Late Cretaceous, and that plumage already served a range of functions in both dinosaurs and birds.

\section{References and Notes}

1. P. G. Davis, D. E. G. Briggs, Geology 23, 783 (1995).

2. D. Schlee, W. Glöckner, Stuttg. Beitr. Naturkd. C 8 1 (1978).

3. J. Alonso et al., J. Paleontol. 74, 158 (2000).

4. V. Perrichot, L. Marion, D. Néraudeau, R. Vullo, P. Tafforeau, Proc. Biol. Sci. 275, 1197 (2008).

5. D. Grimaldi, G. R. Case, Am. Mus. Novit. 3126, 1 (1995).

6. Q. Ji, P. J. Currie, M. A. Norell, S.-A. Ji, Nature 393, 39 (1998)

7. M. Norell, X. Xu, Annu. Rev. Earth Planet. Sci. 33, 277 (2005).
8. X. Xu, Y. Guo, Vertebrata PalAsiatica 47, 311 (2009).

9. R. C. McKellar, A. P. Wolfe, in Biodiversity of Fossils in Amber from the Major World Deposits, D. Penney, Ed. (Siri Scientific Press, Manchester, 2010), pp. 149-166.

10. Materials and methods are available as supporting material on Science Online.

11. R. O. Prum, J. Exp. Zool. 285, 291 (1999).

12. R. O. Prum, A. H. Brush, Q. Rev. Biol. 77, 261 (2002).

13. A. H. Brush, Am. Zool. 40, 631 (2000).

14. P. J. Currie, P.-]. Chen, Can. J. Earth Sci. 38, 1705 (2001).

15. X. Xu, X. Zheng, H. You, Nature 464, 1338 (2010).

16. P. Stettenheim, Living Bird 12, 201 (1973).

17. A. M. Lucas, P. R. Stettenheim, Avian Anatomy: Integument (U.S. Department of Agriculture, Washington, DC, 1972).

18. P.-]. Chen, Z.-M. Dong, S.-N. Zhen, Nature 391, 147 (1998).

19. A. W. A. Kellner et al., Proc. Biol. Sci. 277, 321 (2010).

20. X. Xu, Z.-H. Zhou, R. O. Prum, Nature 410, 200 (2001).

21. T. ]. Cade, G. L. Maclean, Condor 69, 323 (1967)

22. G. L. MacLean, Bioscience 33, 365 (1983).

23. ]. Fjeldså, The Grebes: Podicipedidae (Oxford Univ. Press, New York, 2004)

24. A. C. Chandler, Univ. Calif. Publ. Zool. 13, 243 (1916).

25. C. J. Dove, Ornith. Mono. 51, 1 (2000).

26. P. ]. Currie, in Dinosaur Provincial Park: A Spectacular Ancient Ecosystem Revealed, P. J. Currie, E. B. Koppelhus, Eds. (Indiana Univ. Press, Bloomington, 2005) pp. 367-397.

27. N. Longrich, Cretac. Res. 30, 161 (2009).

28. E. Buffetaut, Geol. Mag. 147, 469 (2010).

Acknowledgments: We thank the Leuck family and M. Schmidt (donated specimens); M. Caldwell, S. Ogg and M. Srayko (microscopy); E. Koppelhus and H. Proctor (discussions); and ]. Gardner, B. Strilisky, A. Howell, and ]. Hudon (TMP, Redpath Museum, and Royal Alberta Museum collections). Research was funded by Natural Sciences and Engineering Research Council of Canada (NSERC) Discovery Grants to B.D.E.C., A.P.W., and P.J.C. and NSERC and Alberta Ingenuity Fund support to R.C.M.

\section{Supporting Online Material}

www.sciencemag.org/cgi/content/ful//333/6049/1619/DC1 Materials and Methods

SOM Text

Figs. S1 to $\mathrm{S} 12$

References (29-49)

25 January 2011; accepted 22 July 2011

10.1126/science. 1203344

\title{
Trace Metals as Biomarkers for Eumelanin Pigment in the Fossil Record
}

\author{
R. A. Wogelius, ${ }^{1,2 *}$ P. L. Manning, ${ }^{1,2,3}$ H. E. Barden, ${ }^{1,2}$ N. P. Edwards, ${ }^{1,2}$ S. M. Webb, ${ }^{4}$ \\ W. I. Sellers, ${ }^{5}$ K. G. Taylor, ${ }^{6}$ P. L. Larson, ${ }^{1,7}$ P. Dodson, ${ }^{3,8}$ H. You, ${ }^{9}$ L. Da-qing, ${ }^{10}$ U. Bergmann ${ }^{11}$
}

Well-preserved fossils of pivotal early bird and nonavian theropod species have provided unequivocal evidence for feathers and/or downlike integuments. Recent studies have reconstructed color on the basis of melanosome structure; however, the chemistry of these proposed melanosomes has remained unknown. We applied synchrotron $\mathrm{x}$-ray techniques to several fossil and extant organisms, including Confuciusornis sanctus, in order to map and characterize possible chemical residues of melanin pigments. Results show that trace metals, such as copper, are present in fossils as organometallic compounds most likely derived from original eumelanin. The distribution of these compounds provides a long-lived biomarker of melanin presence and density within a range of fossilized organisms. Metal zoning patterns may be preserved long after melanosome structures have been destroyed.

$\mathrm{F}$ eather color in birds stems mostly from chemical pigments, of which the most widely used are melanins (1). Resolving

color patterns in extinct species may hold the key to understanding selection processes that acted during crucial evolutionary periods and 
of the heavy and light chains that constitute each antibody. Elements from sets of possible gene regions recombine to encode the heavy and light chains, allowing a vast array of combinatorial possibilities. Each antibody carries a complementarity determining region (CDR) that complements an epitope on a target protein. An antibody-producing B cell begins to proliferate upon recognition of a complementing epitope. During this expansion, in a process called affinity maturation, somatic mutations are focused in the CDR coding regions, generating many slight variants of the antibody. B cells with mutations that improve antibody affinity for its target protein are selected as the immune response matures.

Through modeling of antibody sequences, the lineages leading to effective antibodies can be reconstructed, and $\mathrm{Wu}$ et al. and Scheid et al. show that VRC01-like antibodies favor particular variable genes that encode the CDR. Scheid et al. found that each of 10 CD4bs antibodies isolated from five different patients used one of two closely related germline heavy-chain genes, $\mathrm{VH1}-2$ or $\mathrm{VH1}-46$, and certain light-chain genes were favored; Wu et al. also identified the common precursor VH1-2. Both studies show that the predicted unmutated ancestor for these B cells had weak or no apparent affinity for HIV Env, and subsequent somatic mutation acquisition was essential for the breadth and potency of these antibodies. Variants of VRC01-like antibodies were common in individuals with $\mathrm{BNAb}$ responses. Scheid et al. found multiple VRC01-like antibodies among B cell clones isolated from four HIV-infected individuals. Wu et al. explored the diversity of the B cells from two donors in depth through pyrosequencing and uncovered many highly mutated variant sequences of the same lineage (originating from a common heavy-chain gene, IGHV1-2*02).

Wu et al. and Scheid et al. obtained structures by x-ray crystallography to deduce precise regions of target recognition for representative BNAbs. The structures showed that the antibodies exhibited a highly convergent mode of binding to the CD4bs epitope of gp120 (an Env constituent) despite extensive sequence variation in the antibody CDRs. The BNAbs recognized the same epitope, and the same selective force-affinity for the CD4bs - drove antibody evolution. Thus, the sequences evolved to find distinct answers to recognition of a structurally conserved, but still somewhat variable, epitope (see the first figure). Affinity maturation is associated with reduced entropic cost of antibodyantigen binding (11); fine-tuning of hydrophobic interactions in the BNAbs reported by $\mathrm{Wu}$ et al. may be the basis for increased affinity. VRC01 is not polyreactive $(4,12)$, although this is common among BNAbs (5). Scheid et al. found, however, that $65 \%$ of the related antibodies they isolated were polyreactive, although the germline antibodies they tested were not polyreactive. Thus, the structural plasticity of the antibodies that mediated polyspecificity (13) evolved in conjunction with high affinity for the CD4bs.

Scheid et al. identified common sequence features among VRC01-like antibodies. The contact residues in VRC01 that are the most highly conserved among VRC01-like antibodies from both studies directly interact with highly conserved residues in gp120 of Env (see the second figure). By contrast, contact residues that are more variable among VRC01-like antibodies interact at the periphery of the CD4bs, where residues are less well conserved. Thus, key conserved contacts may be a critical feature of the epitope-antibody interaction that enables neutralization breadth.

Detailed reconstruction of the natural development of BNAbs suggests a new direction for vaccine design: choosing vaccine antigens that trigger ancestral states of antibodies. This is a concept that's time has come. While Wu et al. and Scheid et al. have created a detailed portrait of the evolution and nature of VRC01-like antibodies, parallel investigations have mapped the $\mathrm{B}$ cell lineages of other promising BNAbs that target different regions on HIV Env (14-16). The general approach may be useful for reliably stimulating an initial B cell response from a naïve repertoire when the unmutated ancestor has a low affinity for HIV Env. The logical extension of this-luring an antibody down a controlled affinity maturation pathway by providing antigens that stimulate intermediary states - also becomes an intriguing and hopeful possibility.

\section{References}

1. Q. Abdool Karim et al., CAPRISA 004 Trial Group, Science 329, 1168 (2010).

2. B. Ojikutu, A. T. Makadzange, T. Gaolathe, Curr. HIVIAIDS Rep. 5, 94 (2008).

3. X. Wu et al., Science 333, 1593 (2011); 10.1126/ science. 1207532.

4. J. F. Scheid et al., Science 333, 1633 (2011); 10.1126/ science. 1207227.

5. M. J. McElrath, B. F. Haynes, Immunity 33, 542 (2010).

6. A. J. Hessell et al., Nat. Med. 15, 951 (2009).

7. D. R. Burton et al., Proc. Natl. Acad. Sci. U.S.A. 108, 11181 (2011).

8. I. Mikell et al., PLoS Pathog. 7, e1001251 (2011).

9. X. Wu et al., Science 329, 856 (2010)

10. T. Zhou et al., Science 329, 811 (2010).

11. J. Zimmermann et al., Proc. Natl. Acad. Sci. U.S.A. 103 13722 (2006).

12. Y. Li et al., J. Virol. 85, 8954 (2011).

13. J. Bostrom et al., Science 323, 1610 (2009).

14. M. Bonsignori et al., J. Virol. (2011). 10.1128/ JVI.05045-11.

15. B. J. Ma et al., PLoS Pathog. 7, e1002200 (2011).

16. X. Xiao, W. Chen, Y. Feng, D. S. Dimitrov, Viruses 1, 802 (2009)

10.1126/science.1211919

\section{PALEONTOLOGY}

\section{Fossilized Feathers}

\section{Mark A. Norell}

The evolution of feather color, structure, and organization is gleaned from amber-preserved specimens.

$\mathrm{N}$ ot long ago, extinct dinosaurs were considered by most as scaly and dull. All the known fossils of primitive birds (stem avians) could easily fit on a desk and our only look at Mesozoic [250 to 65 million years ago (Ma)] feathers (except for a few isolated plumes) was Archaeopteryx, a theropod dinosaur considered by most to be the most primitive bird (see the figure). How things have changed-now it would take a warehouse to store all the feathered Mesozoic stem birds and nonavian dinosaurs that have been collected from global deposits. Feathered animals abound and extend deep into nonavian history-

Division of Paleontology, American Museum of Natural His tory, New York, NY 10024, USA. E-mail: norell@amnh.org even, perhaps, to the base of dinosaurs themselves. Now, instead of scaly animals portrayed as usually drab creatures, we have solid evidence for a fluffy colored past. Two reports in this issue, by McKellar et al. (1) on page 1619 and Wogelius et al. (2) on page 1622 , provide a glimpse of the color patterning in the feathers of ancient birds.

Despite many reports over the past decade of feathered dinosaurs and new birds from China, only now are we beginning to understand just how diverse feather types were in the Mesozoic $(3,4)$. The feathers of today's birds are incredibly complex structures (5). For decades their origins were a conundrum for evolutionary biologists, even leading Charles Darwin to proclaim "The sight of a feather in a peacock's tail, whenever I gaze 


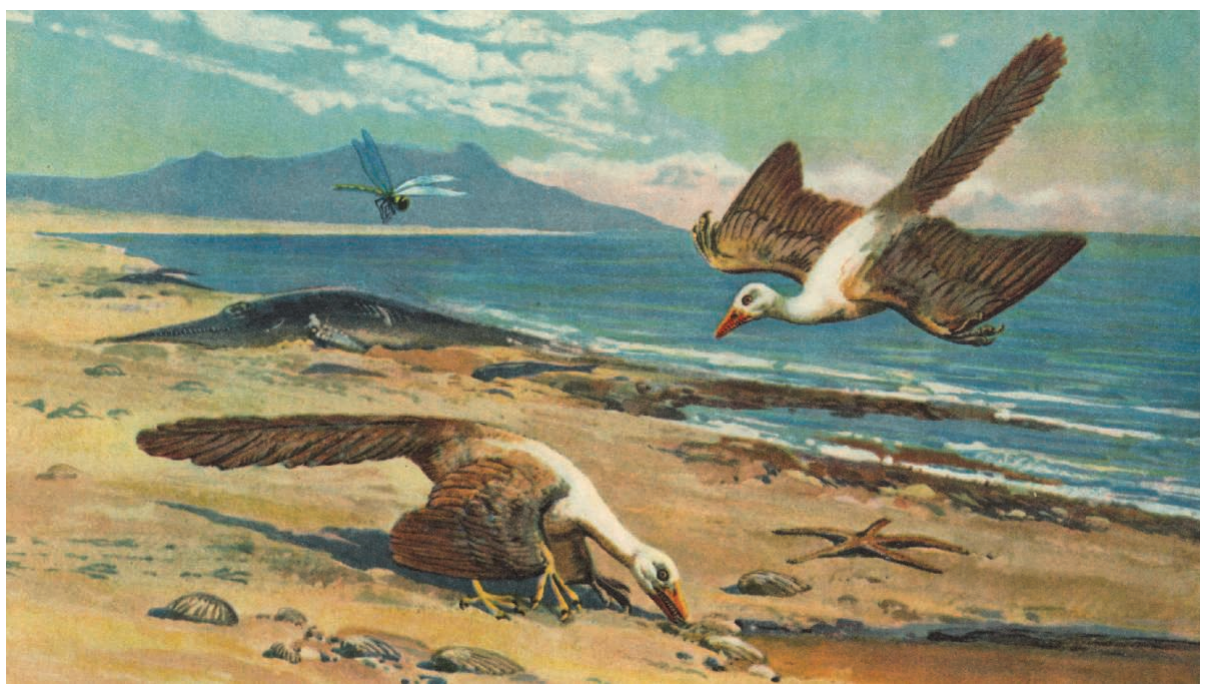

Primitive bird. An old illustration of Archaeopteryx, generally considered to be the most primitive bird.

at it, makes me sick!" (6) when he contemplated the evolution of these structures. The reason for Darwin's dilemma was that the earliest and most primitive feathers found in association with Archaeopteryx were already of modern aspect. The subsequent discovery of several new types of feathers (7) led to an evolutionary series created purely on the basis of phylogenetic information (based on morphology). This series of simple bristles to complex fans agrees nicely with independently developed models suggestive of several stages of feather organization during their evolution $(5,8)$.

The amber-preserved fossils described by McKellar et al. from the Late Cretaceous of Canada (about $70 \mathrm{Ma}$ ) show that a diversity of primitive and advanced feather morphologies were present in a Late Cretaceous ecosystem. Earlier examples of feathers from Late Cretaceous (90 to $94 \mathrm{Ma}$ ) amber (9) did not display such diversity. Amber preserves not only the microstructure, but actual visual color as well-features not preserved in typical compression fossils. All of the feather organizational types are represented in the fossils described by McKellar et al.: primitive stage 1 filaments like those from China most commonly associated with compsognathids and tyrannosaurids; stage 2 clusters found in all sorts of theropod dinosaurs but best known in dromaeosaurs; and other feather types typical of modern birds. Most unexpected is a feather with barbules (the structures that act like Velcro to keep feathers self-organized and neat) that are tightly coiled around their bases. In modern birds these are associated with diving behavior in birds such as grebes. These indicate that the diversity of feathers first identified in the Late Jurassic (160 to
$145 \mathrm{Ma}$ ) and Early Cretaceous not unexpectedly continues to the Late Cretaceous and that complex "modern" feather adaptations had already appeared before the extinction of the nonavian dinosaurs.

Wogelius et al. show how new technology can detect minute geochemical traces and reveal the coloring of these animals. Color in extant bird feathers is conferred by several factors, including pigmentation and structure. These are somewhat intertwined, but pigment is primarily caused by specialized cells (melanosomes) that concentrate organometallic compounds (compounds like carotenoids may also influence color). Other color patterns (like the iridescent gorgets of male hummingbirds) are due to structural characteristics; light reflected by the feathers causes interference effects, producing flashy colors.

In a few cases, excellent preservation allows comparison of the shape of fossil melanosomes with those in extant bird feathers. In the Mesozoic, these have primarily focused on the Early Cretaceous bird Confuciusornis (10) and a few nonavian dinosaurs [like Anchiornis (11) and Sinosauropteryx], which are closely related to modern birds. These studies suggested that Confuciusornis (10) had a rather ruddy reddish topcolor and some countershading, that Sinosauropteryx had a reddish banded tail, and that Anchiornis was almost woodpecker-like with a black body, banded wings, and reddish head comb.

In living birds, melanosomes are of two types: Eumelanosomes are dark brown or black, and phenomelanosomes are reddish brown. Wogelius et al. found dense populations of eumelanosomes across the back and wings, and even evidence of banding on the proximal wing, but there was no evidence for the presence of phenomelanosomes in any of the samples they looked at, including several fossil feathers and a fossil squid. This is surprising because other studies of feathered dinosaurs and even the recent study of a much younger fossil penguin report positive evidence for the presence of phenomelanosomes (12).

However, even though the lack of identification of phenomelanosomes is troubling, Wogelius et al. raise the interesting prospect that feather coloration may be determined even when physical (e.g., visual) evidence for feathers (or even melanosomes) is lacking because what is being mapped are trace organometallic biomarkers. They argue that this technique may be superior because the shapes and sizes of melanosomes can be altered during the millions of years in which a fossil specimen lies buried and that entire specimens can be analyzed, obviating the need for analyses that alter or destroy the sample.

Research into fossil feathers is still at a nascent stage. In the last couple of years, feathers or feather-like structures have been found that represent the earliest stages of dinosaur evolution. Now we are filling in the colors. Feathers, perhaps even brightly colored ones, may be primitive for dinosaurs [the discovery of the feathered ornithischian Tianyulong (13) supports this] and pterosaurs and may even extend to the base of the archosaur tree (14). We will hopefully improve on contemporary fanciful dinosaur reconstructions by basing revisions directly on quantifiable results. The studies by McKellar et al. and Wogelius et al. are way stations toward this goal.

\section{References}

1. R. C. McKellar, B. D. E. Chatterton, A. P. Wolfe, P. J. Currie, Science 333, 1619 (2011).

2. R. A. Wogelius et al., Science 333, 1622 (2011); 10.1126/science.1205748.

3. M. A. Norell, X. Xu, Annu. Rev. Earth Planet. Sci. 33, 277 (2005).

4. X. Y. Xu, Vertebrata PalAsiatica 47, 311 (2009)

5. R. O. Prum, J. Exp. Zool. B 304B, 570 (2005).

6. F. Darwin, Ed., Letter to Asa Gray, dated 3 April 1860, The Life and Letters of Charles Darwin (John Murray, London, 1887), vol. 2, p. 296; (D. Appleton and Company, New York and London, 1911), vol. 2, pp. 90-91.

7. J. Qiang, P. J. Currie, M. A. Norell, J. Shu-An, Nature 393 753 (1998).

8. R. O. Prum, A. H. Brush, Q. Rev. Biol. 77, 261 (2002).

9. D. Grimaldi, G. R. Case, Am. Mus. Novit. 3126, 1 (1995)

10. F. Zhang et al., Nature 463, 1075 (2010).

11. Q. Li et al., Science 327, 1369 (2010).

12. J. A. Clarke et al., Science 330, 954 (2010).

13. X.-T. Zheng, H.-L. You, X. Xu, Z.-M. Dong, Nature 458 , 333 (2009).

14. S. L. Brusatte et al., Earth Sci. Rev. 101, 68 (2010). 